\title{
M odified Ninhydrin reagent for the detection of amino acids on TLC plates
}

\author{
A malendu Sinhababu \\ Natural Product Laboratory, Department of Chemistry,The University of Burdwan, Burdwan-713 104 (WB), INDIA \\ E-mail: sinhababu04@yahoo.co.in \\ Received:D ecember 29, 2012; Revised received:F ebruary 25, 2013; Accepted: M arch 20, 2013
}

\begin{abstract}
Ninhydrin is the most well known spray reagent for identification of amino acids due to its high sensitivity. But, it produces same purple/violet color with all amino acids, except proline and hydroxy proline. A new spray reagent, para bromobenzoic acid has been introduced here which produces distinguishable colors with the amino acids with moderately high sensitivity $(0.01-1.0) \mu \mathrm{g}$. A probable mechanism for such color formation has also been proposed.
\end{abstract}

Keywords: Amino acids, Ninhydrin, p-Bromobenzoic acid, Thin-layer chromatography

\section{INTRODUCTION}

Identification of amino acids has utmost importance for the evaluation of protein structure and also for the determination of the presence of amino acids in numerous natural products. There are several methods for the determination of amino acids in biological and pharmaceutical samples. Thin layer chromatography (TLC) finds its place when the relatively costly equipment required by other methods is unavailable. Thin layer chromatography is an important tool for the identification of amino acids by various spray reagents (Lorenz and Flatter, 1970; Devaux and Mesnard, 1971; Wolski et al., 1980; Distler and Fresenius, 1981; Laskar and Basak, 1988; 1990; Basak and Laskar, 1990; Laskar et al. 1991; 2001a,b,c; Basak et al., 1993; Sinhababu et al., 1994; 2013; Khawas and Laskar 2003a,b; Khawas et al., 2004; Samanta et al., 2004; Samanta and Laskar, 2006; Das et al., 2010; Sahana et al., 2011). Of the reagents in general use, ninhydrin is the most popular because of its remarkably high sensitivity (Stahl, 1969). However, ninhydrin produces the same purple/violet color with most amino acids (only proline and hydroxyproline produce yellow color). In present study, an effort has been made to resolve this color problem by modified ninhydrin reagent for the identification of aminoacids.

\section{MATERIALS AND METHODS}

Chromatography plates $(20 \times 20 \mathrm{~cm}$; thickness $0.1 \mathrm{~mm})$ were prepared with silica gel G (Merck, India) using Unoplan Coating apparatus (Shandon, London, U.K.). Standard amino acids were obtained from Sigma (U.S.A) and n- propanol from Merck (India): Reagent I: $0.1 \%$ pbromobenzoic acid (Aldrich Chemical Co., U.S.A.) in ethanol, Reagent II: $0.25 \%$ ninhydrin (Sigma, St. Louis, MO, U.S.A.) in acetone.
Detection of aminoacids on TLC plates: Standard solutions $\left(1 \mathrm{mg} \mathrm{mL}^{-1}\right)$ of amino acids were prepared in $0.01 \mathrm{~mol} \mathrm{~L}^{-1}$ phosphate buffer ( $\mathrm{pH}$ 8.0) and spotted on the TLC plates by means of a graduated micropipette $(5 \mu \mathrm{L})$. The solutions were diluted according to the required spot concentration. Plates were air-dried and subjected to TLC with n- propanol-water, 70:30 (v/v) as mobile phase. After development plates were dried and sprayed with the reagent I and then heated at $110^{\circ} \mathrm{C}$ for $10 \mathrm{~min}$ in an oven. Plates were cooled and then sprayed with reagent II and colors were noted (Table 1). Colors were further observed after heating the plates at $110^{\circ} \mathrm{C}$ for $10 \mathrm{~min}$ (Table 1). Colors were observed visually. Detection limits for the amino acids after use of ninhydrin reagent alone is also given in Table 1.

\section{RESULTS AND DISCUSSION}

To develop color reagents for the detection of amino acids on TLC plates, a lot of work has been done in this context and a good number of modified spray reagents have been developed. The DDQ (Sinhababu et al., 1994) and 2,3-Dichloro-1,4-Naphthaquinone (Khawas et al., 2004) are the two important reagents that can be used alone instead of ninhydrin in this respect. Some complex reagents have also been developed by other workers (Das et al., 2010; Sahana et al., 2011) but their detection limits and color contrasts are not so good enough than some other reagents referred here. Recently, we have also introduced some p-haloderivatives as the modified spray reagents (Sinhababu et al., 2013). In our continuous effort for the development of color reagents, the present author is now able to introduce one more reagent (p-bromobenzoic acid) with high sensitivities for easy and rapid identification of amino acids on TLC chromatoplates. The reagent is capable of developing 
Table 1. Color formation of amino acids on TLC plates with para bromobenzoic-ninhydrin.

\begin{tabular}{|c|c|c|c|c|c|c|}
\hline \multirow{3}{*}{ Amino acids } & \multicolumn{4}{|c|}{ Reagent I + Ninhydrin } & \multirow{3}{*}{$\begin{array}{c}\text { Detection } \\
\text { limit of } \\
\text { Ninhydrin } \\
(\mu \mathrm{g})\end{array}$} & \multirow{3}{*}{$\begin{array}{c}R_{f} \\
\text { values }\end{array}$} \\
\hline & \multicolumn{2}{|c|}{$\begin{array}{c}\text { Cold condition } \\
\text { (before second heating) }\end{array}$} & \multicolumn{2}{|c|}{$\begin{array}{l}\text { H ot condition } \\
\text { (after second heating) }\end{array}$} & & \\
\hline & Color observed & $\begin{array}{l}\text { D etection } \\
\text { limit }(\mu \mathrm{g})\end{array}$ & Color observed & $\begin{array}{l}\text { Detection } \\
\text { limit }(\mu \mathrm{g})\end{array}$ & & \\
\hline Glycine & Saffron & 0.05 & Reddish brown & 0.05 & 0.001 & 0.32 \\
\hline Alanine & Pinkish violet & 0.05 & Reddish pink & 0.04 & 0.009 & 0.37 \\
\hline Valine & Pinkish violet & 0.04 & Pink & 0.03 & 0.010 & 0.45 \\
\hline Leucine & Pinkish violet & 0.05 & Dirty pink & 0.04 & 0.010 & 0.55 \\
\hline Isoleucine & Pinkish violet & 0.04 & Pinkish violet & 0.04 & 0.200 & 0.53 \\
\hline Serine & Dirty pink & 0.20 & Pink & 0.05 & 0.008 & 0.35 \\
\hline Threonine & Pink & 0.20 & Reddish pink & 0.10 & 0.050 & 0.37 \\
\hline Aspartic acid & Gray & 1.00 & Grayish violet & 0.10 & 0.100 & 0.33 \\
\hline Asparagine & Straw yellow & 0.40 & Deep yellow & 0.10 & 0.100 & 0.14 \\
\hline Glutamic acid & Deep pink & 0.60 & Pink & 0.10 & 0.040 & 0.35 \\
\hline Glutamine & Reddish pink & 0.20 & Dirty pink & 0.10 & 0.100 & 0.15 \\
\hline Lysine & Pinkish violet & 0.01 & Pinkish violet & 0.01 & 0.005 & 0.03 \\
\hline Histidine & Pink & 0.20 & Brown & 0.10 & 0.050 & 0.20 \\
\hline Arginine & Pinkish violet & 0.04 & Reddish pink & 0.04 & 0.010 & 0.02 \\
\hline Phenyl alanine & Pink & 1.00 & Saffron & 0.50 & 0.050 & 0.58 \\
\hline Tyrosine & Pale rose & 0.80 & Pale rose & 0.50 & 0.030 & 0.57 \\
\hline Tryptophan & Pink & 1.00 & Gray & 1.00 & 0.050 & 0.62 \\
\hline Cysteine & Pink & 0.10 & Light pink & 0.10 & 0.020 & 0.38 \\
\hline Cystine & Reddish pink & 0.50 & Pale cream & 0.30 & 0.010 & 0.32 \\
\hline Methionine & Reddish pink & 0.40 & Reddish pink & 0.20 & 0.010 & 0.51 \\
\hline Proline & Lemmon yellow & 0.40 & Brownish yellow & 0.10 & 0.100 & 0.26 \\
\hline Hydroxy proline & Pinkish violet & 0.10 & Rosy pink & 0.10 & 0.050 & 0.34 \\
\hline
\end{tabular}

${ }^{a}$ Stahl (1969); ${ }^{\mathrm{b}}$-propanol $:$ water $=70: 30(\mathrm{v} / \mathrm{v})$

various distinguishable colors with many amino acids and also shows high sensitivity (0.01-1.0 $\mu \mathrm{g})$ comparable to ninhydrin alone.

It was observed that ninhydrin gives various distinguishable colors with amino acids in the presence of reagent I before and after final heating. The detection limits $\left(\mu \mathrm{g} \mathrm{spot}^{-1}\right)$ are substantially low $(0.01-1.00 \mu \mathrm{g})$ which is quite comparable to ninhydrin alone. Color development is somewhat different almost in all the cases after second heating. In most cases the detection limits are either equal or a little higher than those obtained after final heating. Such color formations with high sensitivities of this modified spray reagent make it somewhat more useful than ninhydrin spray in the identification of amino acids on TLC plates (Table 1).

The mechanism leading to such color formation is uncertain but a possibility may be ascertained. One possibility is the formation of a secondary amide by the reaction between p-bromobenzoic acid with amino acids and the product thus obtained forms coloring complexes (charge transfer) with ninhydrin, colors of which are variable depending on the nature of the amino acids (Foster, 1969).

\section{ACKNOWLEDGEMENT}

Author is thankful to CAS, UGC, New Delhi, India, for financial assistance.

\section{REFERENCES}

Basak, B. and Laskar, S. (1990). Spray reagent for the detection of amino-acids on thin-layer Plates. Talanta, 37:1105-1106.

Basak, B., Bhattacharya, U.K. and Laskar, S. (1993). Spray reagent for the detection of amino acids on thin layer chromatography plates. Amino Acids, 4:193-196.

Das, D., Sahana, A., Saha, R., Kundu, P. and Laskar, S. (2010). Anthracene-anchored derivatized methionine: A new ligand for detection of amino acids, and estimation of binding constants. J ournal of Planar Chromatography, 23:255-259.

Devaux, G. and Mesnard, P. (1971). Mechanism of the color reaction between ascorbic acid and amino acids. Bulletin of the Society of Pharmaceutical Sciences B ordeaux, 110:145151.

Distler, W. and Fresenius, Z. (1981). 1-Chloro-7-nitrobenzoic1, 2, 5 oxadiazolein Spruhreagenszur Fluoreszenz-Detection 
von Aminosauren auf Dunnschicht-Chromatogrammen. Analytical C hemistry, 309:127-128.

Foster, R. (1969). Organic charge transfer complexes, Academic Press, New York.

Khawas, S. and Laskar, S. (2003a). A reagent for the detection of amino acids on thin layer chromatography plates. Asian J ournal of Chemistry, 15:512-514.

Khawas, S. and Laskar, S. (2003b). Two new spray reagents for the detection of amino acids on thin- layer plates. J ournal of Planar Chromatography, 16:165-166.

Khawas, S., Panja, D. and Laskar, S. (2004). Identification of amino acids on TLC plates with a new reagent. J ournal of Planar Chromatography, 17:314-315.

Laskar, S. and Basak, B. (1988). Detection of amino acids on thin-layer plates. J ournal of Chromatography, 436:341-343.

Laskar, S. and Basak, B. (1990). Identification of amino acids with ninhydrin in acid media. Journal of Planar Chromatography, 3:535-536.

Laskar, S., Bhattacharya, U. and Basak, B. (1991). Modified ninhydrin spray reagent for the identification of amino acids on thin-layer chromatography plates. Analyst, 116:625-626.

Laskar, S., Sinhababu, A. and Hazra, K.M. (2001a). A modified spray reagent for the identification of amino acids on thin layer chromatography plates. J ournal of Indian Chemical Society, 78:49-50.

Laskar, S., Panja, D. and Sinhababu, A. (2001b). A spray reagent for identification of amino acids on thin-layer chromatography plates. J ournal of Planar Chromatography, 14:462-463.

Laskar, S., Sinhababu, A. and Hazra, K.M. (2001c). A modified spray reagent for the detection of amino acids on thin layer chromatography plates. Amino Acids, 21:201-204.

Lorentz, K. and Flatter, B. (1970). Staining of amino acids with benzoquinone in paper chromatography. Analytical Biochemistry, 38:557-559.

Samanta, T.D., Nag, M. and Laskar, S. (2004). A new spray reagent for identification of amino acids on thin-layer chromatography plates. Asian J ournal of Chemistry, 16:1947-1949.

Samanta, T.D. and Laskar, S. (2006). New reagent for detection of amino acids on TLC plates. Journal of Planar Chromatography, 19:252-254.

Sahana, A., Das, S., Saha, R., Gupta, M., Laskar, S. and Das, D. (2011). Identification and interaction of amino acids with leucine-anthracene reagent by TLC and spectrophotometry:experimental and theoretical studies. J ournal of Chromatographic Science, 49:652-656.

Sinhababu, A., Basak, B. and Laskar, S. (1994). Novel spray reagent for identification of amino acids on thin-layer chromatography plates. Analytical Proceedings Including Analytical Communications, 31:65-66.

Sinhababu, A., Basak, B., Dey, H. and Laskar, S. (2013). Identification of amino acids with modified ninhydrin reagents on thin layer chromatography plates. J ournal of Planar Chromatography, 26:26-30.

Stahl, E. (1969). Thin layer chromatography: A laboratory handbook ( $2^{\text {nd }}$ ed) Springer, New York.

Wolski, T., Golkiewicz, W. and Rompola, A. (1980). 4-N, Ndimethyl aminoazobenzene-4-sulfonyl chloride-a high sensitive reagent for the spectrophotometric and chromatographic analysis of amino acids. Chemical Analysis (Warsaw), 25:583-590. 